\title{
Mean and yearly changes in blood pressure with age in the metabolic syndrome: the DESIR study
}

\author{
Michel E Safar ${ }^{1,2,3}$, Céline Lange ${ }^{4,5}$, Jacques Blacher ${ }^{1,2,3}$, Eveline Eschwège ${ }^{4,5}$, Jean Tichet ${ }^{6}$ \\ and Beverley Balkau ${ }^{4,5}$, the DESIR Study Group ${ }^{6}$
}

Systolic and diastolic blood pressure (SBP; DBP) increase with age, but after 45 years of age, the yearly change in DBP ( $\triangle D B P$ ) tends to be smaller in comparison with the yearly change in SBP ( $\triangle S B P$ ), which increases with age. The effect of the metabolic syndrome (MetS) on this yearly change has never been explored. In a 9-year longitudinal cohort Data from an Epidemiologic Study on the Insulin Resistance syndrome (DESIR) study, we examined 1308 men and 1325 women, aged 30-65 years, who had never been treated for hypertension. SBP and DBP were measured at four examinations 3 years apart, and pulse pressure (PP) and yearly changes ( $\triangle \mathrm{SBP}, \triangle \mathrm{DBP}$ and $\triangle \mathrm{PP}$ ) were calculated. SBP and PP increased with age to a higher degree in patients with the MetS. In men and women with the MetS, DBP remained nearly constant, but in those without the MetS, DBP increased. After adjusting for baseline values, $\triangle S B P$ and $\triangle P P$ increased by $0.5 \mathrm{~mm} \mathrm{Hg}$ per year for every additional 10 years from baseline. These correlations with age were similar for men and women, and the yearly change was always higher than in those with the MetS. In contrast, $\triangle D B P$ increased very slowly until 50 years of age and then decreased similarly for those with and without the MetS. The increase in PP with age, a marker of vascular aging, was determined to begin earlier in the present study than has been shown in the past, and the MetS amplified this effect. This new aspect of the MetS might modify clinical management leading to earlier drug treatment, particularly in regard to both endothelial dysfunction and increased arterial stiffness.

Hypertension Research (2011) 34, 91-97; doi:10.1038/hr.2010.180; published online 7 October 2010

Keywords: aging; arterial stiffening; blood pressure; epidemiology; metabolic syndrome

\section{INTRODUCTION}

The metabolic syndrome (MetS), a major risk factor for cardiovascular (CV) morbidity and mortality, is defined by three or more of the following clinical characteristics: abdominal obesity, hyperglycemia, high blood pressure, hypertriglyceridemia and hypo-high-density lipoprotein-cholesterolemia. ${ }^{1,2}$ Increased aortic stiffness, one of the major mechanical factors predicting CV risk, ${ }^{2}$ has been identified in individuals with the MetS.,3 The level of arterial stiffness, and particularly its rate of progression with age, is proportional to the number of $\mathrm{CV}$ risk factors involved in the diagnosis of the syndrome. ${ }^{3}$ In CV pathology, increased aortic stiffness with age is partly responsible for both an increase in aortic systolic blood pressure (SBP) and a decrease in diastolic blood pressure (DBP), which are the two main hemodynamic characteristics of hypertension in the elderly. ${ }^{2,4}$ Whereas high SBP is associated with cardiac hypertrophy, low DBP contributes to coronary ischemia. Thus, both factors contribute to the prevalence of $\mathrm{CV}$ events and are of major importance in the prognosis of the MetS.
The Data from an Epidemiologic Study on the Insulin Resistance syndrome (DESIR) cohort included $>5200$ men and women aged 30-65 years. Participants were evaluated every 3 years for a total of 9 years of follow-up. ${ }^{1,5}$ In this French study, high blood pressure was the most frequent abnormality of those with the MetS: 70\% in men and $47 \%$ in women at inclusion. ${ }^{1}$ From this long-term survey, it is possible to evaluate not only the mean values of SBP, DBP, mean blood pressure $(\mathrm{MBP}=\mathrm{SBP} / 3+2 / 3 \mathrm{DBP})$ and pulse pressure $(\mathrm{PP}=\mathrm{SBP}-\mathrm{DBP})$ in successive age groups, but also the slope (yearly change) of the change in SBP, DBP and PP per unit year $(\triangle \mathrm{SBP}, \triangle \mathrm{DBP}$ and $\triangle \mathrm{PP})$, in both men and women, according to age at baseline.

From DESIR and other investigations, ${ }^{1-5}$ it has been shown that mean SBP and DBP increase progressively with age. At around 50-60 years of age, the mean values of SBP continue to increase with age, whereas the mean values of DBP tend to increase at a lower rate. We have recently shown that the yearly change in DBP, $\triangle \mathrm{DBP}$, occurs much earlier than changes in the level of DBP itself, that is, before the age of 50-60 years. ${ }^{5}$ An important consequence of this observation

\footnotetext{
${ }^{1}$ Université Paris Descartes, Paris, France; ${ }^{2}$ Assistance Publique-Hôpitaux de Paris, Paris, France; ${ }^{3}$ Centre de Diagnostic et de Thérapeutique, Hôtel-Dieu, Paris, France; 4 INSERM CESP Center for Research in Epidemiology and Population Health U1018, Epidemiology of Diabetes, Obesity and Chronic Kidney Disease over the Lifecourse, Villejuif, France; ${ }^{5}$ Université Paris-Sud 11, Villejuif, France and ${ }^{6}$ Institut inter Régional pour la Santé, La Riche, France

Correspondence: Dr ME Safar, Centre de Diagnostic et de Thérapeutique, Université Paris Descartes, Hôtel-Dieu, 1 place du Parvis Notre Dame, Paris Cedex 04, 75181, France. E-mail: michel.safar@htd.aphp.fr

Received 25 April 2010; revised 12 July 2010; accepted 21 July 2010; published online 7 October 2010
} 
might be that $\triangle \mathrm{DBP}$, and hence $\triangle \mathrm{PP}$, differs markedly in many pathological circumstances, such as in the MetS. This may help scientists to better understand vascular aging and the prevalence of $\mathrm{CV}$ events. Our working hypothesis is that such circumstances might occur in the MetS.

The goal of this analysis in the DESIR cohort was to investigate the relationship among SBP, DBP and $\mathrm{PP}$ as well as among $\triangle \mathrm{SBP}, \triangle \mathrm{DBP}$ and $\triangle \mathrm{PP}$ with age at baseline and to compare these correlations between individuals both with and without the MetS at baseline.

\section{METHODS}

\section{Participants}

Between 1994 and 1996, 5212 participants were recruited from 10 health examination centers among volunteers insured by the French Social Security system, which offers periodic health examinations free of charge. ${ }^{1,5}$ The protocol was approved by the 'Comite Consultatif de la Protection des Personnes pour la Recherche Biomédicale' of Bicêtre Hospital, Paris, and participants signed an informed consent. This analysis included 1308 men and 1325 women who had never been treated with drugs for hypertension and who had blood pressures measured at baseline and three follow-up examinations.

\section{Measures}

Blood pressures were measured in the supine position after a 5-min rest. Both at inclusion and at the 3-year follow-up examinations, a mercury sphygmomanometer was used, and at the 6- and 9-year examinations, an OMRON HEM-705CP was used. According to the validation study of O'Brien et al., ${ }^{6}$ this device measures SBP $2 \mathrm{mmHg}$ and DBP $1 \mathrm{mmHg}$ lower than a standard mercury sphygmomanometer. We have modified the corresponding blood pressures accordingly. Participants were lightly clad, and weight and height were measured to allow for calculation of body mass index (weight/height ${ }^{2}$ $\left.\left(\mathrm{kg} \mathrm{m}^{-2}\right)\right)$. The waist was measured at the smallest circumference between the lower ribs and the iliac crests.

All biochemical measurements were from one of the four health center biological laboratories located in France at Blois, Chartres, La Riche or Orléans. Total cholesterol, high-density lipoprotein-cholesterol and triglycerides were assayed by DAX 24 (Bayer Diagnostics, Puteaux, France) or KONE (Evry, France). The fasting plasma glucose, measured by the glucose-oxidase method, was applied to fluoro-oxalated plasma using a Technicon RA100 (Bayer Diagnostics) or a Specific or Delta device (Konelab, Evry, France). The interlaboratory variability was assessed monthly with normal and pathological values for each biologic variable; the coefficients of variation for laboratories were $<6 \%$ over the inclusion period.

Information about current smoking, alcohol intake and the use of drugs for hypertension were collected from self-administered questionnaires.

\section{Definition of the MetS}

The presence of the MetS was defined according to the National Cholesterol Education Program-Adult criteria ${ }^{7}$ as three or more of the following characteristics:

- waist circumference $>102 / 88 \mathrm{~cm}$, men/women;

- fasting glucose $\geqslant 6.1 \mathrm{mmoll}^{-1}$ or diabetic treatment;

- $\mathrm{SBP} \geqslant 130 \mathrm{~mm} \mathrm{Hg}$ and/or DBP $\geqslant 85 \mathrm{~mm} \mathrm{Hg}$;

- triglycerides $\geqslant 1.69 \mathrm{mmoll}^{-1}$;

- high-density lipoprotein-cholesterol $<1.04 / 1.29 \mathrm{mmoll}^{-1}$, men/women

This definition does not include treatment for hypertension or lipids, and thus treatment for hypertension or hyperlipidemia does not add to the syndrome count. In addition, this definition was used to individually study the effect of each of the five syndrome components and their relationship with yearly changes in blood pressure.

\section{Statistical methods}

Each individual in our study was characterized by his age, SBP, DBP, MBP and PP at baseline, and by his yearly change in SBP, DBP, MBP and PP: $\triangle \mathrm{SBP}, \triangle \mathrm{DBP}$, $\triangle \mathrm{MBP}$ and $\triangle \mathrm{PP}$ in $\mathrm{mmHg}$ per year. As indicated above, we included only participants for whom there were blood pressure measurements from all four examinations. The yearly change was calculated from the slope of a line drawn between blood pressure and age at baseline. Characteristics of the participants at inclusion and the yearly change in blood pressures were studied, according to sex and to the presence of the MetS at baseline (Tables 1 and 2). Outcomes were compared by $t$ - and $\chi^{2}$-tests; interaction tests for differences between genders used analysis of variance and logistic regression.

Pearson correlation coefficients were used to quantify the relationship between blood pressures and their yearly changes.

The mean SBP, DBP and PP at baseline and the yearly change in $\Delta$ SBP, $\triangle \mathrm{DBP}$ and $\triangle \mathrm{PP}$ were modeled by linear regression, separately for men and women, according to baseline age (as a continuous parameter) and the presence of the MetS. Likelihood ratio tests were used to determine whether the relationships with baseline age were linear or curvilinear, by the addition of a squared term in age. These relationships are shown graphically, with the modeled curve (either linear or quadratic with baseline age) and the observed data as points, and with standard errors by 5-year age groups (Figures 1 and 2). We compared the relationship between groups with and without the MetS, using likelihood ratio tests; the regressions are shown in the figures with (1) separate curves or lines or with (2) a combined curve or line if they did not differ significantly according to the presence of the MetS. For the yearly change in blood pressures, adjustments were made for the corresponding mean baseline blood pressure in the study population. The effect of individual MetS components was judged by the modeled change in yearly blood pressures: $\triangle \mathrm{SBP}, \triangle \mathrm{DBP}$ and $\triangle \mathrm{PP}$.

A change in the intercept point without any change in slope indicated a shift of the curve. A change in the slope indicated a change in the sensitivity of the system. Analyses used SAS Version 9.1 (SAS Institute, Cary, NC, USA).

\section{RESULTS}

\section{Mean values of brachial SBP, DBP and PP at inclusion} by age and sex

As expected, individuals with the MetS were older than those without, and all other parameters, with the exception of height in men and smoking and alcohol intake in women, comprised a worse profile in subjects with MetS than in those without the MetS at inclusion (Table 1). There was a difference in the effect of the MetS between men and women (a significant interaction) for SBP, MBP and PP, but not for DBP, which demonstrated that the MetS had a larger effect in women than in men.

Mean SBP increased linearly with age (Figure 1) in both men and women and was significantly higher $(P<0.0001)$ in individuals with MetS than without the MetS; there was a difference of $7 \mathrm{~mm} \mathrm{Hg}$ for men, the same at all ages, and a difference of $14 \mathrm{~mm} \mathrm{Hg}$ for women.

In subjects with the MetS, mean DBP was fairly constant with age, but in subjects without the MetS, mean DBP increased linearly in both men and women (Figure 1). DBP was significantly higher $(P<0.0001)$ in those with MetS than in those without.

The mean PP increased curvilinearly with age (Figure 1) and was similar for those with and without MetS. For men with MetS, PP was $6 \mathrm{~mm} \mathrm{Hg}$ higher and for women it was $7 \mathrm{~mm} \mathrm{Hg}$ higher; this was true for all ages.

\section{Mean yearly change in $\triangle S B P, \triangle D B P$ and $\Delta P P$ by age at inclusion and sex}

For men and women with the MetS, the yearly change in $\mathrm{PP}, \Delta \mathrm{PP}$, was higher in comparison to those without the MetS, but there was no difference for $\triangle \mathrm{SBP}, \triangle \mathrm{DBP}$ and $\triangle \mathrm{MBP}$ (Table 2). After adjustment for the corresponding blood pressure at baseline, $\triangle \mathrm{SBP}$ in both 
Table 1 Clinical and biological characteristics (mean (s.d.) or $n(\%)$ ) of the men and women, according to the presence/absence of the metabolic syndrome at inclusion (the DESIR study)

\begin{tabular}{|c|c|c|c|c|c|c|c|}
\hline & \multicolumn{3}{|c|}{ Men } & \multicolumn{3}{|c|}{ Women } & \multirow[b]{2}{*}{$\begin{array}{c}\text { Sex-interaction } \\
\text { P-value }\end{array}$} \\
\hline & $\begin{array}{c}\text { Metabolic syndrome } \\
\text { absent }(\mathrm{n}=1225)\end{array}$ & $\begin{array}{c}\text { Metabolic syndrome } \\
\text { present }(\mathrm{n}=83)\end{array}$ & $\mathrm{P}$-value & $\begin{array}{c}\text { Metabolic syndrome } \\
\text { absent }(\mathrm{n}=1291)\end{array}$ & $\begin{array}{c}\text { Metabolic syndrome } \\
\text { present }(\mathrm{n}=34)\end{array}$ & P-value & \\
\hline Age (years) & $45(10)$ & $48(10)$ & 0.004 & $46(10)$ & $50(11)$ & 0.007 & 0.4 \\
\hline BMI $\left(\mathrm{kg} \mathrm{m}^{-2}\right)$ & $24.5(2.6)$ & $28.8(3.4)$ & 0.0001 & $23.1(3.4)$ & $29.8(5.1)$ & 0.0001 & 0.0001 \\
\hline Weight (kg) & $74(9)$ & $86(11)$ & 0.0001 & $59(9)$ & $75(13)$ & 0.0001 & 0.08 \\
\hline Height (cm) & $173(7)$ & $173(6)$ & 0.9 & $160(6)$ & $158(6)$ & 0.04 & 0.1 \\
\hline Waist circumference $(\mathrm{cm})$ & $87(8)$ & $99(9)$ & 0.0001 & $74(8)$ & $93(10)$ & 0.0001 & 0.0001 \\
\hline Systolic blood pressure (mm Hg) & $130(12)$ & $137(11)$ & 0.0001 & $123(12)$ & $139(12)$ & 0.0001 & 0.0004 \\
\hline Diastolic blood pressure (mm Hg) & $80(8)$ & $85(8)$ & 0.0001 & $75(8)$ & $83\left(\&^{2} \& 7\right)$ & 0.0001 & 0.1 \\
\hline Mean blood pressure $(\mathrm{mm} \mathrm{Hg})$ & $96(8)$ & $103(8)$ & 0.0001 & $91(9)$ & $102(7)$ & 0.0001 & 0.01 \\
\hline Pulse pressure $(\mathrm{mm} \mathrm{Hg})$ & $50(9)$ & $52(9)$ & 0.09 & $48(8)$ & $56(10)$ & 0.0001 & 0.0005 \\
\hline Heart rate (b.p.m.) & $65(10)$ & $68(9)$ & 0.01 & $68(9)$ & $74(9)$ & 0.0001 & 0.08 \\
\hline Fasting glucose $\left(\mathrm{g} \mathrm{I}^{-1}\right)$ & $0.97(0.09)$ & $1.11(0.26)$ & 0.0001 & $0.92(0.10)$ & $1.03(0.17)$ & 0.0001 & 0.3 \\
\hline Cholesterol $\left(\mathrm{gl}^{-1}\right)$ & $2.22(0.36)$ & $2.37(0.41)$ & 0.0003 & $2.15(0.37)$ & $2.31(0.40)$ & 0.01 & 0.9 \\
\hline HDL-cholesterol ( $\mathrm{gl}^{-1}$ ) & $0.60(0.15)$ & $0.43(0.10)$ & 0.0001 & $0.71(0.16)$ & $0.52(0.13)$ & 0.0001 & 0.4 \\
\hline Triglycerides $\left(\mathrm{gl}^{-1}\right)^{\mathrm{a}}$ & $0.98(0.49)$ & $2.09(0.69)$ & 0.0001 & $0.75(0.36)$ & $1.65(0.69)$ & 0.0001 & 0.7 \\
\hline Smoking $(n, \%)$ & $308(25 \%)$ & $29(35 \%)$ & 0.05 & $178(14 \%)$ & $4(12 \%)$ & 0.7 & 0.3 \\
\hline Alcohol intake (g per day) & $23.0(22.2)$ & $30.1(25.6)$ & 0.01 & $6.9(11.0)$ & $6.5(10.4)$ & 0.9 & 0.2 \\
\hline
\end{tabular}

Abbreviations: BMI, body mass index; DESIR, Data from an Epidemiologic Study on the Insulin Resistance syndrome; HDL, high-density lipoprotein.

aLog transformation for statistical analyses.

Table 2 The change per year in systolic blood pressure ( $\triangle \mathrm{SBP}$ ), diastolic blood pressure ( $\triangle \mathrm{DBP}$ ) and pulse pressure ( $\triangle \mathrm{PP}$ ), according to the presence/absence of the metabolic syndrome at inclusion and assuming a linear model over time for these blood pressure parameters (the DESIR Study)

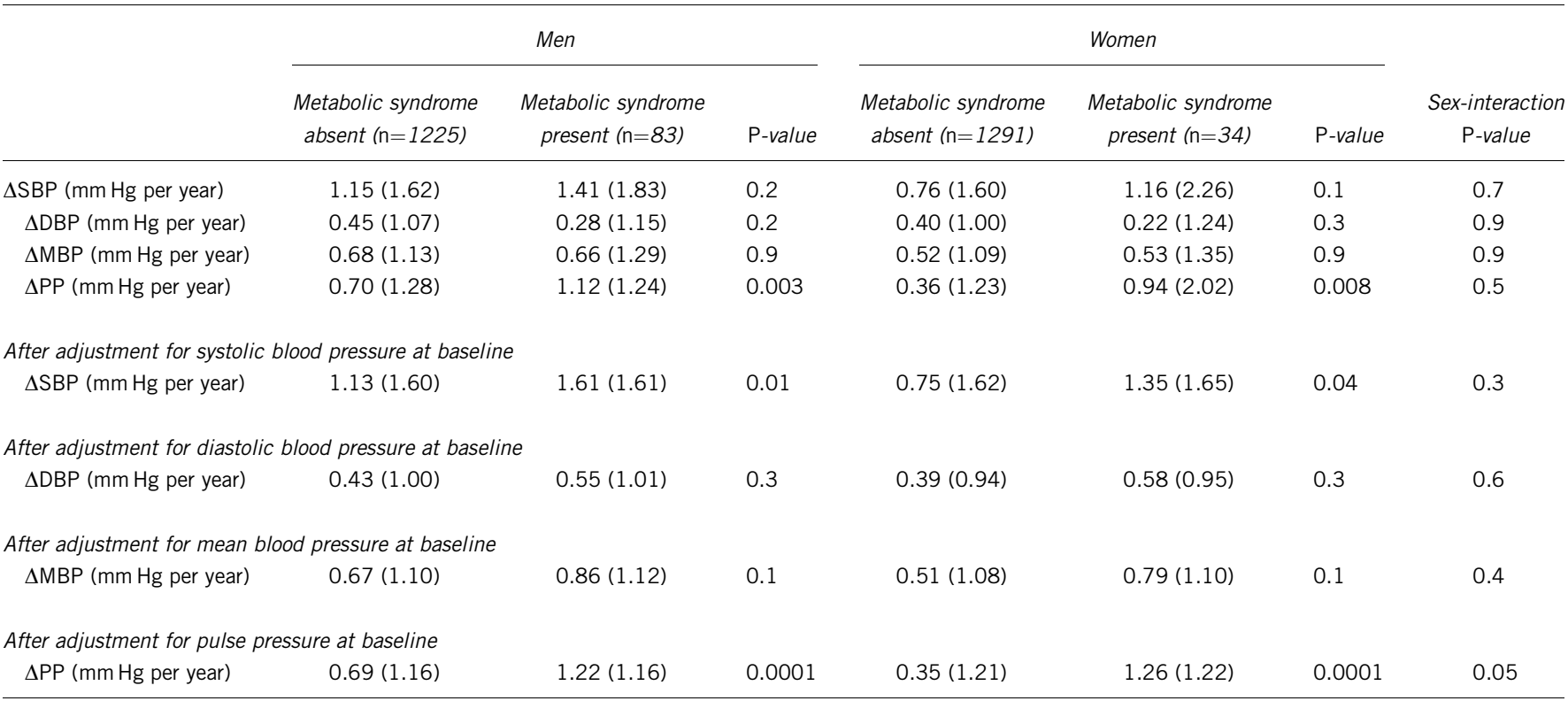

Abbreviations: DESIR, Data from an Epidemiologic Study on the Insulin Resistance syndrome; MBP, mean blood pressure.

men and women with the MetS was significantly higher than those without MetS $(P<0.01$ and 0.04 , respectively), and $\Delta \mathrm{PP}$ was higher by $0.53 \mathrm{~mm} \mathrm{Hg}$ per year in men and by $0.91 \mathrm{~mm} \mathrm{Hg}$ per year for women (both $P<0.0001$ ) with MetS in comparison to those without.

The yearly changes in blood pressure were negatively correlated with baseline blood pressures, and the strongest correlations were for DBP. Pearson correlation coefficients between SBP and $\triangle$ SBP were -0.20 for men and -0.08 for women; for DBP and $\triangle \mathrm{DBP}$, Pearson coefficients were -0.38 and -0.36 , respectively; and for $\mathrm{PP}$ and $\Delta \mathrm{PP}$, coefficients were -0.41 and -0.26 , respectively. All values were statistically significant with $P<0.0001$.

$\triangle$ SBP increased linearly with baseline age for both men and women with and without the MetS. The yearly change was identical: $0.45 \mathrm{~mm} \mathrm{Hg}$ per year for a 10 -year difference from baseline age (Figure 2). $\triangle \mathrm{SBP}$ was $0.44 \mathrm{~mm} \mathrm{Hg}$ per year higher in men with the MetS than in those without $(P<0.0001)$ and $0.43 \mathrm{~mm} \mathrm{Hg}$ per year higher in women with the MetS than in those without. 
Mean systolic blood pressure $(\mathrm{mmHg})$ at inclusion
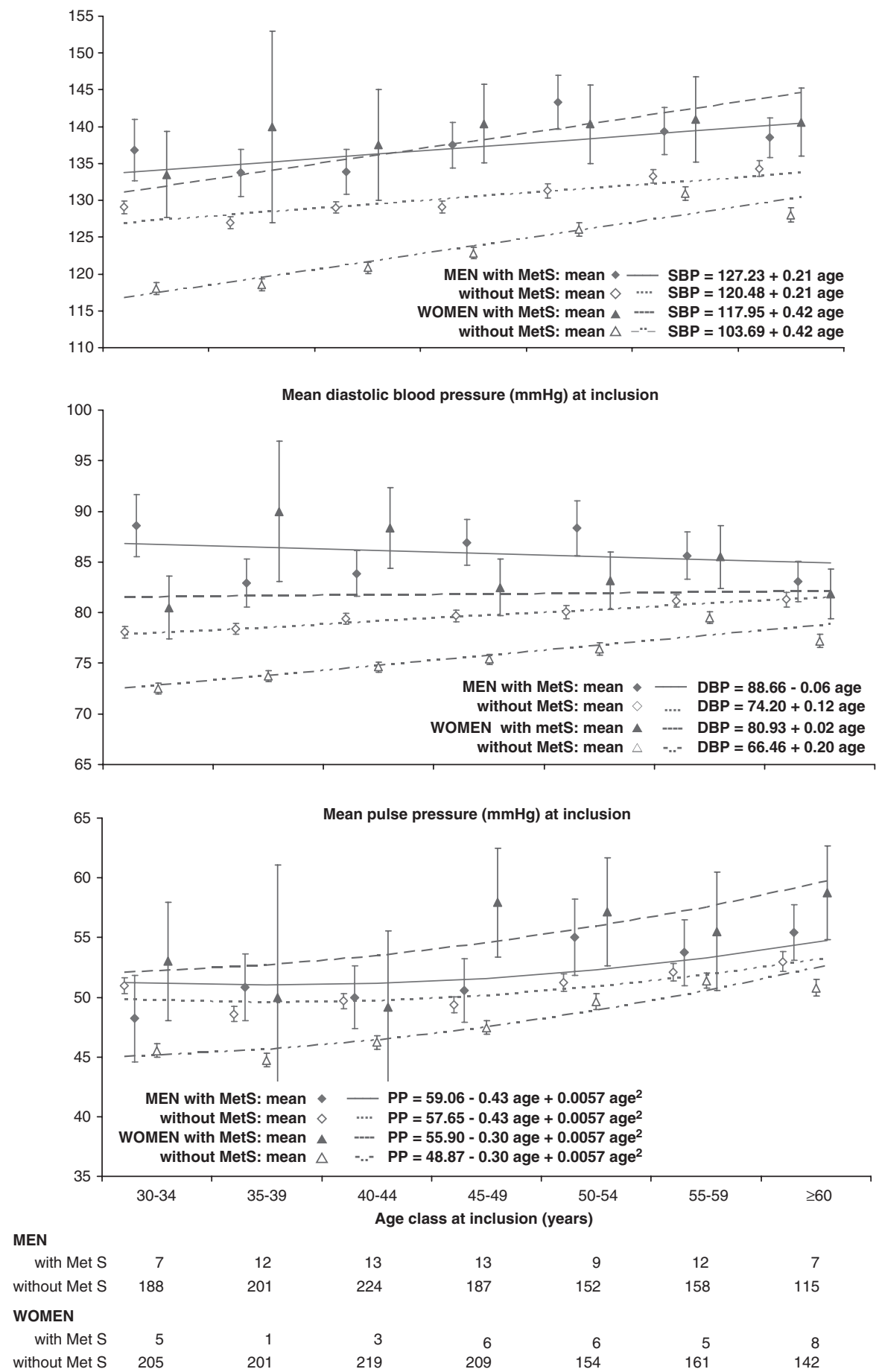

Figure 1 Mean systolic blood pressure (SBP), diastolic blood pressure (DBP) and pulse pressure (PP) according to baseline age and the absence/presence of the National Cholesterol Education Program-Adult (NCEP) metabolic syndrome (MetS) in men and women. The Data from an Epidemiologic Study on the Insulin Resistance syndrome (DESIR) study.

In contrast, $\triangle \mathrm{DBP}$ showed a curvilinear relationship with baseline age in men and women (Figure 2), identical in those with and without the MetS, and women had a lower change per year than men, $0.25 \mathrm{~mm} \mathrm{Hg}$ per year.

Mean $\triangle \mathrm{PP}$ increased linearly with age in both men and women (Figure 2) at the same rate, independent of the presence of the MetS, at $0.48 \mathrm{~mm} \mathrm{Hg}$ per year per 10 -year difference from baseline age.
However, the yearly change was higher in men and women with the MetS than in those without.

For $\triangle \mathrm{SBP}$, the triglycerides and waist-size components of subjects with the MetS were the strongest contributors to the MetS, whereas for $\triangle \mathrm{DBP}$ and $\triangle \mathrm{PP}$, the blood pressure and waist components were the strongest contributors. 

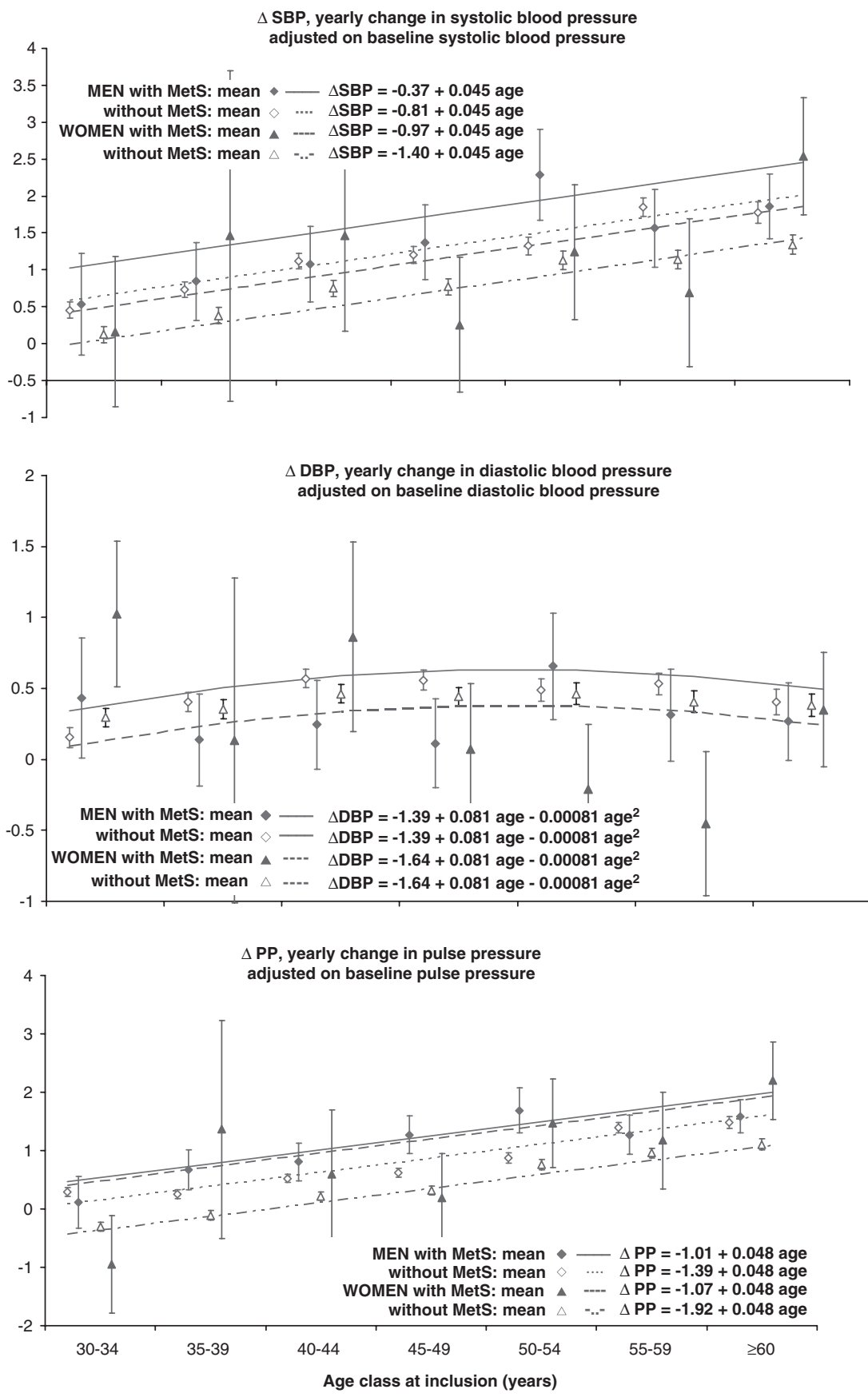

MEN

\begin{tabular}{|c|c|c|c|c|c|c|c|}
\hline with Met S & 7 & 12 & 13 & 13 & 9 & 12 & 7 \\
\hline without Met S & 188 & 201 & 224 & 187 & 152 & 158 & 115 \\
\hline \multicolumn{8}{|l|}{ WOMEN } \\
\hline with Met S & 5 & 1 & 3 & 6 & 6 & 5 & 8 \\
\hline without Met S & 205 & 201 & 219 & 209 & 154 & 161 & 142 \\
\hline
\end{tabular}

Figure 2 Mean yearly change in systolic blood pressure $(\Delta \mathrm{SBP})$, diastolic blood pressure $(\Delta \mathrm{DBP})$ and pulse pressure $(\Delta \mathrm{PP})$ according to baseline age and the absence/presence of the National Cholesterol Education Program-Adult (NCEP) metabolic syndrome (MetS) in men and women after adjusting for baseline blood pressure. The Data from an Epidemiologic Study on the Insulin Resistance syndrome (DESIR) study. Note that men and women with the syndrome have similar relationships between $\triangle \mathrm{PP}$ and age with intercepts at -1.01 and -1.07 , respectively. Note also that for $\triangle \mathrm{DBP}$, men with the syndrome have the same relationship as men without the syndrome, and the same is true for women. This relationship is demonstrated by the curves.

\section{DISCUSSION}

In this analysis of the DESIR study, which included 1308 men and 1325 women aged 30-65 years at baseline, we investigated the relationships between baseline age and SBP, DBP and PP as well as correlations with the rate of change in SBP, DBP and PP according to the presence or absence of the MetS. In this context, it has been well established that at around 55-60 years of age, SBP increases with age, whereas DBP tends to decrease, thus resulting in an increasing 
PP with age. ${ }^{1-5}$ In a previous longitudinal study, we have shown that as early as $40-45$ years, the yearly change in SBP and DBP is significantly modified. Although $\triangle \mathrm{SBP}$ increased markedly and linearly with age, $\triangle \mathrm{DBP}$ decreased in a curvilinear manner in both men and women. This longitudinal study shows that in the presence of the MetS, the yearly changes in SBP and PP are substantially higher at all baseline ages.

Blood pressure (SBP, DBP, MBP and PP) is always higher in people with the MetS in comparison with others, regardless of age and sex. However, in individuals with the MetS, although SBP and PP continue to increase with age, DBP is relatively constant. Surprisingly, women with the MetS had a higher PP than men with the MetS, a difference that increased with age; however, in those without the MetS, women had a lower PP at all ages when compared with men, but the mean PP was similar after 50 years.

In addition, in the presence or absence of the MetS, $\triangle \mathrm{SBP}$ and $\triangle \mathrm{PP}$ increased linearly with age, whereas $\triangle \mathrm{DBP}$ showed a curvilinear relation with baseline age as early as 50 years in both men and women. In the presence of the MetS, there was a significant shift of $\triangle \mathrm{SBP}$ toward higher values, whereas for $\triangle \mathrm{DBP}$, there was no difference in those with and without the MetS, resulting in higher values of $\triangle \mathrm{PP}$. Men and women with the MetS had an almost identical $\Delta \mathrm{PP}$ with age, whereas for those without the syndrome, the $\Delta \mathrm{PP}$ was $0.53 \mathrm{~mm} \mathrm{Hg}$ per year in men, more than in women.

A limitation of this study is that mercury sphygmomanometers were used for the first two blood pressure measurements and an OMRON device was used for the subsequent two measurements. We verified that this change did not modify the hypertensive classification of the overall population, and our longitudinal study demonstrated results similar to those previously reported. ${ }^{1,5}$ The principal limitation of the investigation was the site used for blood pressure measurements: the brachial artery. ${ }^{1}$ Brachial SBP must be considered a local parameter. As a consequence of the propagation of a pressure wave along the arterial tree and the presence of wave reflections, the brachial SBP is significantly higher than the central SBP, except in people above 50 years of age. ${ }^{1-3}$ However, SBP at the brachial artery site is more reproducible than brachial DBP, which includes error due to its technical measurement. In contrast, DBP is nearly the same for the entire arterial tree. ${ }^{8}$ Furthermore, in this study, we used an OMRON device that is known to predict CV risk very adequately. ${ }^{6}$ Finally, we know that the brachial DBP satisfactorily reflects central DBP and may be considered an index of coronary perfusion pressure. ${ }^{8,9}$ This finding is of primary importance in the present study, which emphasizes the role of DBP and $\triangle \mathrm{DBP}$.

In this article, we have studied a very specific population: those who have never been treated with medications for hypertension. Thus, we studied the natural history of blood pressure. If we had included treatments, then the results could not have been interpreted so easily.

Our data show that although $\triangle \mathrm{SBP}$ increased continuously with baseline age, beginning as early as 30-34 years of age, $\triangle \mathrm{DBP}$ tended to increase until 50 years and then to decrease; hence $\Delta \mathrm{PP}$ increased with age. Such changes are typical consequences of increased arterial stiffness. ${ }^{3}$ In subjects with the MetS, this hemodynamic pattern is considerably accentuated, which is an expected result based on the accelerated progression of arterial stiffness with age and a finding also observed in people with the MetS. ${ }^{10}$ Undoubtedly, in both men and women, the changes in $\triangle \mathrm{DBP}$ predominate over those of SBP. We suggest that for $\triangle \mathrm{DBP}$, there is a balance between the increase in arterial stiffness, which tends to decrease DBP and $\triangle \mathrm{DBP}$, and several particularities of the MetS, which may tend to increase DBP and $\triangle \mathrm{DBP}$.
The most important characteristic of the MetS is an early and progressive inability of peripheral vascular networks to adequately perfuse skeletal muscle during periods of elevated metabolic activity. ${ }^{10}$ Results of experimental and clinical studies indicate that nitric-oxidedependent stimuli and hypoxia, together with augmented constriction to $\alpha$-adrenergic and myogenic stimuli, participate greatly in the observed changes. The resulting consequences include endothelial dysfunction, oxidative stress and inflammation. In the microvascular network, this process involves structural arteriolar changes and capillary rarefaction, which in turn are associated with an increase in both SBP and DBP. In the macrocirculation, a similar process accelerates arterial stiffness, which favors an increase in SBP but a decrease in DBP. Finally, in the MetS, DBP is the result of these two different mechanisms.

In conclusion, we have shown on the basis of $\triangle \mathrm{SBP}, \triangle \mathrm{DBP}$ and $\triangle \mathrm{PP}$ in the MetS, that vascular aging begins much earlier ( $45-50$ years) than was believed in the past. This process helps to amplify the CV risk through progressive systolic and diastolic hypertension in individuals over 45 years of age. This new aspect of the MetS might modify clinical management, leading to earlier drug treatment, particularly in regard to two important disorders: endothelial dysfunction and increased arterial stiffness.

\section{ABBREVIATIONS}

DBP, diastolic blood pressure; DESIR, Data from an Epidemiological Study on the Insulin Resistance syndrome study; MBP, mean blood pressure; MetS, metabolic syndrome; PP, pulse pressure; SBP, systolic blood pressure; $\Delta \mathrm{SBP}$, $\Delta \mathrm{DBP}, \Delta \mathrm{PP}$, yearly change in systolic blood pressure, diastolic blood pressure, pulse pressure.

\section{CONFLICT OF INTEREST}

The authors declare no conflict of interest.

\section{ACKNOWLEDGEMENTS}

We thank INSERM, CNAMTS, Lilly, Novartis Pharma, Sanofi-Aventis, Association Diabète Risque Vasculaire, Fédération Française de Cardiologie, La Fondation de France, ALFEDIAM, ONIVINS, Groupe de Pharmacologie et d'Hémodynamique Cardiovasculaire, Ardix Medical, Bayer Diagnostics, Becton Dickinson, Cardionics, Merck Santé, Novo Nordisk, Pierre Fabre, Roche, Sanofi-Aventis, Topcon.

THE DESIR STUDY GROUP: INSERM-U780: B Balkau, P Ducimetière, E Eschwège; INSERM-U367: F Alhenc-Gelas; CHU-D’ANGERS: Y Gallois, A Girault; HOPITAL-BICHAT: F Fumeron, M Marre; CHU Rennes: F Bonnet; CNRS UMR8090: LILLE: P Froguel; CENTRES D’EXAMENS DE SANTÉ: Alençon, Angers, Blois, Caen, Chartres, Chateauroux, Cholet, Le Mans, Orléans, Tours; INSTITUT DE RECHERCHE EN MÉDECINE GÉNÉRALE: J Cogneau; MEDECINS GÉNERALISTES des Départements; INSTITUT INTER-RÉGIONAL POUR LA SANTÉ: C Born, E Cacès, M Cailleau, JG Moreau, F Rakotozafy, J Tichet, S Vol.

1 Balkau B, Vernay M, Mhamdi L, Novak M, Arondel D, Vol S, Tichet J, Eschwège E, DESIR Study Group. The incidence and persistence of the NCEP (National Cholesterol Education Program) metabolic syndrome. The French DESIR Study. Diabetes Metab 2003; 29: 526-532.

2 Safar ME, O'Rourke MF (eds). Handbook of Hypertension, 23rd edn Elsevier: Edinburgh, 2006, pp 3-62, 379-398.

3 Safar ME, Thomas F, Blacher J, Nzietchueng R, Bureau JM, Pannier B, Benetos A. Metabolic syndrome and age-related progression of aortic stiffness. J Am Coll Cardio 2006; 47: 72-75.

4 Franklin SS, Gustin VI W, Wong ND, Larson MG, Weber MA, Kannel WB, Levy D. Hemodynamic patterns of age-related changes in blood pressure. The Framingham Heart Study. Circulation 2007; 96: 308-315.

5 Safar ME, Lange C, Tichet J, Blacher J, Eschwège E, Balkau B, the D.E.S.I.R. Study Group, France. The Data from an Epidemiologic Study on the Insulin Resistance 
Syndrome Study: the change and the rate of change of the age-blood pressure relationship. J Hypertens 2008; 26: 1903-1911.

6 O'Brien E, Mee F, Atkins N, Thomas M. Evaluation of three devices for self-measurement of blood pressure according to the revised British Hypertension Society Protocol: the Omron HEM-705CP, Philips HP5332, and Nissei DS-175. Blood Press Monit 1996; 1: 55-81.

7 Executive Panel on Detection Evaluation Treatment of High Blood Cholesterol in Adults Executive. Summary of the Third Report of the National Cholesterol Education Program (NCEP) Expert Panel on Detection, Evaluation, and Treatment of High Blood Cholesterol in Adults (Adult Treatment Panel III). JAMA 2001; 285: 2486-2497.
8 Safar ME, Smulyan H. Systolic versus diastolic blood pressure, In Bulpitt CJ (ed). Handbook of Hypertension, 20th edn Elsevier Science BV: Amsterdam, 2000, pp 73-85.

9 Bobrie G, Chatellier G, Genes N, Clerson P, Vaur L, Vaisse B, Menard J, Mallion JM. Cardiovascular prognosis of 'masked hypertension' detected by blood pressure self-measurement in elderly treated hypertensive patients. JAMA 2004; 29: 1342-1349.

10 Frisbee JC. Hypertension-independent microvascular rarefaction in the obese Zucker rat model of the metabolic syndrome. Microcirculation 2005; 12: 383-392. 